\title{
Lack of evidence for the role of human adenovirus 36 in obesity of Egyptian children
}

\author{
Mehrevan M. Abdel-moniem¹, Ola M. Ibrahim², Azza A. Gabr², EL-Sonousy WM², \\ Manal A. Mohsen², Fawzia A. Hassaballah², Ali Abdel Aziz², Heba El Malt ${ }^{1}$
}

\begin{abstract}
${ }^{1}$ Medical Biochemistry Department, National Research Centre, Giza, Egypt
${ }^{2}$ Child Health Department, National Research Centre, Giza, Egypt

${ }^{3}$ Water Pollution Department, National Research Centre, Giza, Egypt
\end{abstract}

Submitted: 29 September 2018

Accepted: 9 December 2018

Arch Med Sci Civil Dis 2018; 3: e210-e216

DOI: https://doi.org/10.5114/amscd.2018.81308

Copyright @ 2018 Termedia \& Banach

\section{Abstract}

Introduction: Obesity has become the most prevalent chronic disorder that affects large populations, particularly children, all over the world. Although the cause of obesity has largely been considered to be multifactorial, the concept of a viral origin has been relatively understudied, in comparison with genetic and behavioral causes. Emerging evidence supports adenovirus 36 (Ad 36) as a potential cause of human obesity. We aimed to examine whether Ad 36 infection is associated with obesity and lipid disorders in Egyptian children.

Material and methods: One hundred and thirty children and adolescents were included in this study; 80 of them were obese and 50 were controls. All participated in physical and clinical examination. Personal habits of nutrition, anthropometric measurements, and laboratory parameters including plasma glucose, insulin, HOMA-IR index, lipid profile and Ad 36-specific neutralizing antibodies were assessed.

Results: Food habit inquiries revealed that $70 \%$ of all children had snacks before lunch, which were significantly higher in carbohydrates and fats in obese subjects $(p=0.009)$. No significant difference in lipid profile was found between the 2 groups. Obese children had significantly higher levels of insulin and HOMA-IR index than the controls. Adenovirus 36 IgG was positive in only 2 of the obese children. Age was positively correlated with BAZ, insulin levels and HOMA index $(r=0.29, p<0.001 ; r=0.29, p=0.001$ and $r=0.22, p=0.013$, respectively). A positive correlation between insulin and BAZ $(r=0.24, p=0.007)$ was found.

Conclusions: No association was found between obesity and infection with Ad 36 in Egyptian children, indicating that Ad 36 has a limited effect as a causative agent of obesity in the Egyptian community.

Key words: adenovirus 36, obesity, children.

\author{
Corresponding author: \\ Prof. Mehrevan M. \\ Abdel-moniem \\ Medical Biochemistry \\ Department \\ National Research \\ Centre \\ El-Tahrir St \\ 12622 Giza, Egypt \\ Phone: +201152111484 \\ E-mail: sunrisemoh@yahoo. \\ com
}

\section{Introduction}

The incidence of obesity in recent decades has grown dramatically [1]. The worldwide prevalence of obesity more than doubled between 1980 and 2014 [2]. For children who remain obese into young adulthood, life expectancy may be shortened by as much as 20 years [3]. Egypt is the fattest African country, with nearly $70 \%$ of its adult population overweight or obese. It is also the $14^{\text {th }}$ fattest country in the world, according to the most recent World Health Organization statistics. In addition to the health care costs, there are costs to society of obesity-related ab- 
senteeism and loss of productivity from school or work [4]. The prevalence of obesity in Egyptian children ranged from $13.5 \%$ [5] up to $23.7 \%$ [6], and obesity represents one of the major public health problems in Egypt.

The interaction between genetics, metabolic, social, cultural and environmental factors, including viral infection, addresses many different cofactors for the development of obesity. The role of bacteria and viruses as potential etiological agents has been suggested, and the term 'infectobesity' has been proposed [7]. The most widely studied infection agent possibly linked to obesity is adenovirus 36 (Ad 36). It was reported that $\mathrm{Ad} 36$ causes obesity in animals [8]. In humans, some previous studies suggested a correlation of obesity with Ad 36 infection in adults and children $[9,10]$. Studies to confirm or refute the possibility that certain viruses may cause weight gain are required in Egypt. In the meantime, discounting viruses as a contributing factor to obesity would deprive us of a potential new avenue of investigating and treating the ever increasing epidemic of obesity. This study aimed to detect the presence of Ad 36 antibodies in serum of Egyptian children, obese and non-obese, and to find out if there is association between infection with Ad 36 and obesity.

\section{Material and methods}

This study started with clinical examination and anthropometric measurements of one thousand children and adolescents chosen randomly from three governmental schools at Giza. Their age ranged from 9.5 years to 18 years (mean: $14.25 \pm 2.07$ years). The anthropometric measures were computed by the Anthro plus program and the BMI Z score (BAZ) was calculated. According to the $\mathrm{WHO}$, subjects who had $\mathrm{BAZ}>2$ were considered obese. One hundred and thirty children and adolescents gave consent to participate in the study: 80 were obese (39 males and $41 \mathrm{fe}$ males) and 50 with $B A Z \leq 2$ served as the control group ( 23 males and 27 females). Exclusion criteria: were factors that might lead to the misclassification of a child's weight status, that is, (1) an acute or chronic illness affecting weight, (2) genetic conditions associated with obesity or failure to thrive, and/or (3) use of medications associated with weight gain or weight loss. Inclusion criteria: apart from obesity, all obese subjects and normal controls were in good health.

All participants were informed about the objectives of the study and volunteered to participate. The parents of all subjects provided written informed consent.

All participants were subjected to the following: 1) physical and clinical examination; 2 ) respond to a questionnaire on social status, medical history, medications, and personal habits of nutrition; 3) anthropometric assessment: anthropometric parameters that included: body weight (WT), height ( $\mathrm{Ht})$, and waist circumference (WC); 4) fasting blood samples were drawn into 2 vacutainer tubes, one containing EDTA as an anticoagulant. The samples were immediately transferred to the laboratory. Both tubes were centrifuged immediately for $10 \mathrm{~min}$ at 4000 and stored at $-80^{\circ} \mathrm{C}$ for future laboratory investigations.

\section{Anthropometric assessment}

Weight, height, and body mass index (BMI) were expressed as weight-for-age Z-score (WAZ), heightfor-age Z-score (HAZ), and BMI-Z-score after being calculated according to the WHO standards using Anthro Plus software of the WHO (2009).

\section{Biochemical investigations}

Lipid profile: triglycerides (TG) and total cholesterol (TC) levels were assayed by enzymatic colorimetric methods [11]. High-density lipoprotein cholesterol (HDL-C) concentrations were measured by enzymatic assay after phosphotungstic acid and magnesium precipitation [12]. Low-density lipoprotein cholesterol (LDL-C) was calculated using the Friedewald equation when the triglyceride concentrations did not exceed $408 \mathrm{nmol} / \mathrm{l}$ [13]: LDL-C $=\{$ total cholesterol $-\mathrm{HDL}-\mathrm{C}-$ (triglyceride/5) $\}$.

Serum glucose level was also determined by the glucose oxidize method $[14,15]$.

Serum insulin was measured using the quantitative enzyme-linked immunosorbent assay (ELISA) using a commercial kit provided by DIA source, Belgium [16]. The Homeostasis Model Assessment (HOMA-IR) method was used for the calculation of insulin resistance. This method has been validated as a reliable measure of insulin resistance in vivo in humans. The HOMA-IR method closely mirrors the glucose clamp technique in the assessment of insulin sensitivity [17]. Higher HOMA-IR scores denoted lower insulin sensitivity and greater insulin resistance.

\section{Assessment of adenovirus 36}

The presence of Ad 36-specific neutralizing antibodies was assessed using the serum neutralization assay: Samples were concentrated by filtration through negatively charged nitrocellulose membranes (ALBET, Spain $0.45 \mu \mathrm{m}$ pore size and $142 \mathrm{~mm}$ diameter filter series) after addition of $\mathrm{AlCl}_{3}$ to a final concentration of $0.5 \mathrm{mM}$ and acidification to $\mathrm{pH} 3.5$ and after passing through Whatman no. 1 filter paper. The viruses adsorbed on the membrane were eluted with $75 \mathrm{ml}$ of $0.05 \mathrm{M}$ glycine buffer, $\mathrm{pH}$ 9.5, containing 3\% beef extract 
(Lab-Limco powder, OXOID, UK) [18, 19]. All samples were re-concentrated using an organic flocculation method [20]. Samples were neutralized and kept at $-70^{\circ} \mathrm{C}$ until used.

\section{Statistical analysis}

Data management and analysis were performed using SPSS version 17. Results were presented as mean \pm SD, except where otherwise indicated. Comparisons between the two groups with respect to numeric variables were done by the Mann-Whitney test. To compare more than two groups with respect to numeric variables, the Kruskal-Wallis test followed by the post hoc Dunn test for non-parametric data was performed. The $\chi^{2}$ test was used to compare the groups with respect to categorical data. To assess the degree of association between the numeric variables, the Spearman correlation for nonparametric data was used. $P$-values $<0.05$ were considered significant

\section{Results}

This study included 1000 students who were subjected to anthropometric measurements. Their age ranged from 9.5 to 18 years (mean: 14.25 \pm 2.07 years).

The results revealed that 130 of them were obese (13\%), $57(43.8 \%)$ of them were girls, and $73(56.2 \%)$ were boys. Eighty of the obese children (39 males and 41 females), and 50 of the normal children (BAZ $\leq 2)$ (23 males and 27 females) had given consent to participate in the study.

The socioeconomic status of the two studied groups is shown in Table I. No significant differences were observed.

Table I. Socioeconomic status of the two studied groups

\begin{tabular}{|lcccc|}
\hline Parameter & \multicolumn{2}{c}{ Control } & \multicolumn{2}{c|}{ Obese } \\
\cline { 2 - 5 } & $N$ & $\%$ & $N$ & $\%$ \\
\hline Mother education: & & & & \\
\hline Not educated & 4 & 8 & 10 & 12.5 \\
\hline Moderate & 6 & 12 & 15 & 18.75 \\
\hline High & 40 & 80 & 55 & 68.75 \\
\hline Mother occupation: & & & & \\
\hline Not working & 34 & 68 & 53 & 66.25 \\
\hline Working & 16 & 32 & 27 & 33.75 \\
\hline Father education: & & & & \\
\hline Not educated & 4 & 8 & 10 & 12.5 \\
\hline Moderate & 5 & 10 & 7 & 8.75 \\
\hline High & 41 & 82 & 63 & 78.75 \\
\hline Father occupation: & & & & \\
\hline Not working & 0 & 0 & 2 & 2.5 \\
\hline Working & 50 & 100 & 78 & 97.5 \\
\hline
\end{tabular}

As regards the food habits of the studied children, the results showed that the usual breakfast food was mainly carbohydrate and fats in both groups. Also, it was noted that $70 \%$ of all subjects received snacks before lunch. However, the snack foods of obese children were significantly higher in carbohydrate and fat as compared to those of normal children $(p=0.01)$ (Figure 1$)$.

Eighty-five percent of the studied children received the dinner meal, but it was found that $33.8 \%$ of the obese had their dinner just before going to bed, compared to $10.3 \%$ of the control group, and the difference was statistically significant $(p=0.01)$. In addition, the percentage of obese children who ate when stressed was significantly higher than that of non-obese children ( $22.9 \%$ vs. $4.7 \%$ respectively, $p=0.002)$. The presence of one or more fat family member was found in $79.3 \%$ of obese children and in $28 \%$ of the control children; that difference was statistically significant $(p<0.001)$. Table II shows the serum levels of lipid profile in obese and control groups; no significant differences were observed.

Fasting blood sugar, serum insulin and HOMA index levels are shown in Table III. Obese children had significantly higher levels of insulin and HOMA index as compared to those of the control children ( $p=0.003$ and $p=0.001$ respectively). It was noted that the percentage of obese children who had early or significant resistance to insulin was higher than that of the control children, but the difference was not statistically significant (Figure 2).

Seventy-six serum samples from obese children were investigated for Ad 36 IgG as an agent for obesity. At the same time 48 serum samples from normal children were also investigated as a control. The results showed that only two samples of obese children (2.6\%) were positive for Ad 36 lgG. At the same time all 48 control samples were negative for Ad 36 lgG.

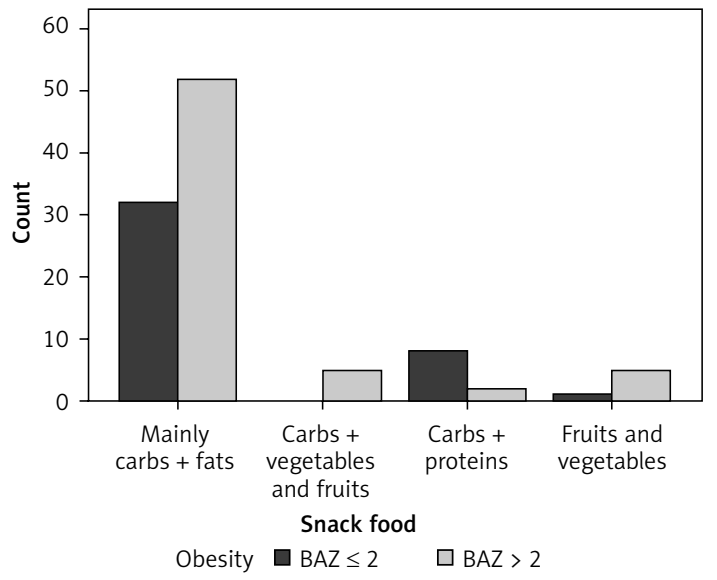

Figure 1. Obese children in association with types of food

Carbs - carbahydrate 
Table II. Serum levels of the lipid profile in the obese and control groups

\begin{tabular}{|c|c|c|c|c|c|}
\hline Parameter & Group & $N$ & Mean & Standard deviation & Sig. $(p)$ \\
\hline \multirow[t]{2}{*}{ Cholesterol [mg/dl] } & Control & 50 & 125.69 & 40.81 & NS \\
\hline & Obese & 80 & 136.88 & 37.98 & \\
\hline \multirow[t]{2}{*}{ Triglyceride $[\mathrm{mg} / \mathrm{dl}]$} & Control & 50 & 66.20 & 26.17 & NS \\
\hline & Obese & 80 & 69.83 & 34.89 & \\
\hline \multirow[t]{2}{*}{$\mathrm{HDL}[\mathrm{mg} / \mathrm{dl}]$} & Control & 50 & 45.64 & 14.96 & NS \\
\hline & Obese & 80 & 44.70 & 11.48 & \\
\hline \multirow[t]{2}{*}{ LDL [mg/dl] } & Control & 50 & 73.56 & 42.94 & NS \\
\hline & Obese & 80 & 84.97 & 71.99 & \\
\hline
\end{tabular}

Table III. Level of glucose, insulin and HOMA index in obese and control groups

\begin{tabular}{|lccccc|}
\hline Parameter & Group & $N$ & Mean & Standard deviation & Sig. $(p)$ \\
\hline Glucose $[\mathrm{mg} / \mathrm{dl}]$ & Control & 50 & 0.2387 & 22.94 & 18.47 \\
\cline { 2 - 6 } & Obese & 80 & 88.27 & 4.47 & $0.003^{*}$ \\
\hline Insulin $[\mu \mathrm{lU} / \mathrm{ml}]$ & Control & 50 & 5.53 & 5.33 & 0.96 \\
\hline HOMA index & Obese & 80 & 8.21 & 1.49 \\
\hline
\end{tabular}

The clinical characteristics and biochemical parameters of the two positive Ad 36 patients are shown in Tables IV and V.

Our results showed that age was positively correlated with level of insulin and HOMA index $(r=$ $0.29, p=0.001$ and $r=0.22, p=0.013$ respectively). Also a positive correlation between insulin and $\operatorname{BAZ}(r=0.24, p=0.007)$ was found (Figure 3$)$.

\section{Discussion}

The present study showed that the prevalence of obesity among children and adolescents from governmental schools aged 9-18 years was 13\%. A previous Egyptian study by Badawi et al. [5] showed a very similar percentage of obese children aged 6-12 years (13.5\%). In 2014 the prevalence of obesity in children aged 5-9 years according to an Egyptan demographic and health survey was $3.9 \%$ [21]. However. a higher percentage of obesity was recorded in the study of Taha and Marawan [6], which was $23.7 \%$ in children aged 8-12 years.

Our results showed that the level of education and employment of both parents had no significant association with obesity. In contrast to our results, the Egyptian study by Badawi et al. [5] showed a significant direct association of socioeconomic class with obesity. Also Chakar and Salameh in Lebanon [22] and Khader et al. in Jordan [23] found that BMI was higher in families with

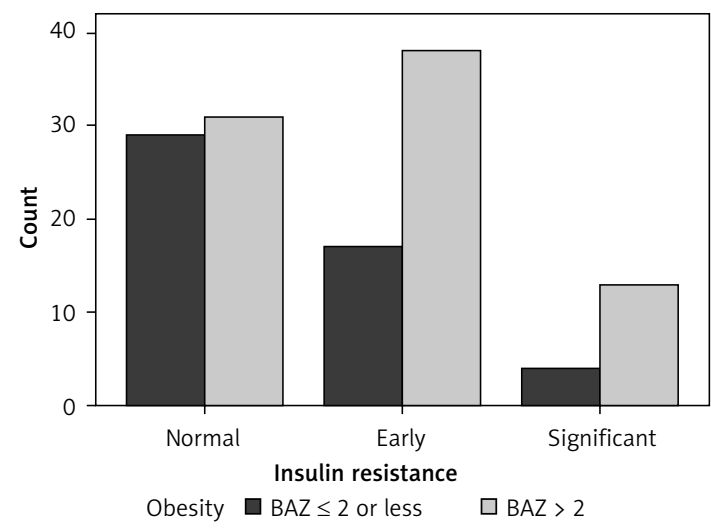

Figure 2. Insulin resistance in obese and control children

a higher socioeconomic level. The absence of association of socioeconomic class with obesity in our study may be due to the lack of clear differences in socioeconomic status between our subjects, as most of them were from nearly the same geographic area.

The unhealthy dietary habits of children included in this study had a great influence on their obesity (Figure 1). Similar findings were previously reported in the study of Taha and Marawan [6].

The present work showed that $79.3 \%$ of obese children had one or more fat family member. Several studies were in agreement with our results. Mo Suwan et al. [24] and Badawi et al. [5] 
Mehrevan M. Abdel-moniem, Ola M. Ibrahim, Azza A. Gabr, EL-Sonousy WM, Manal A. Mohsen, Fawzia A. Hassaballah, Ali Abdel Aziz, Heba El Malt

Table IV. Clinical characteristics of Adv36 positive patients

\begin{tabular}{|lcc|}
\hline Parameter & Patient 1 & Patient 2 \\
\hline Sex & Male & Male \\
\hline Age [years] & 9.8 & Middle \\
\hline Socioeconomic status & Middle & 62.5 \\
\hline Weight [kg] & 42 & 154.5 \\
\hline Height [cm] & $>2$ & $>2$ \\
\hline BMl-Z score (BAZ) & Carbohydrate and fat & Carbohydrate and fat \\
\hline Type of breakfast & Yes & Yes \\
\hline Snack before lunch & Just before sleep & Just before sleep \\
\hline Time of dinner & Mainly carbohydrate & Mainly carbohydrate \\
\hline Type of dinner & 2 (mother and aunt) & Mother
\end{tabular}

Table V. Biochemical parameters of Adv36 positive patients

\begin{tabular}{|c|c|c|c|}
\hline Parameter & Normal range & Patient 1 & Patient 2 \\
\hline Glucose [mg/dl] & $70-120$ & 186 & 82.6 \\
\hline Cholesterol [mg/dl] & $<200$ & 220 & 142.9 \\
\hline $\mathrm{TC}[\mathrm{mg} / \mathrm{dl}]$ & $40-160$ & 90 & 94.9 \\
\hline $\mathrm{HDL}[\mathrm{mg} / \mathrm{dl}]$ & $30-70$ & 48 & 50 \\
\hline LDL [mg/dl] & $<130$ & 154 & 73.92 \\
\hline Insulin $[\mu \mathrm{U} / \mathrm{ml}]$ & $<10$ & 5.1 & 2.4 \\
\hline HOMA index (IR) & $\begin{array}{c}<1-\text { normal } \\
1-2.8-\text { early insulin resistance } \\
>2.8 \text { - significant resistance }\end{array}$ & 2.34 & 0.37 \\
\hline
\end{tabular}

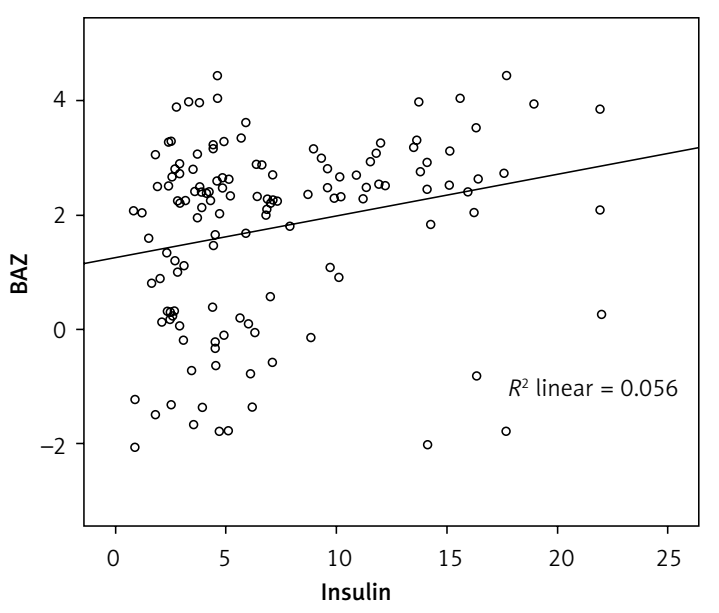

Figure 3. Correlation between insulin level and BAZ

mentioned a strong positive correlation between obese children and BMI of their parents.

Regarding lipid profile, this study demonstrated that serum cholesterol and LDL were higher in obese children than in controls, but the differenc- es were not statistically significant. In addition, the mean levels of triglyceride and HDL were almost the same in both groups.

Similar findings were previously reported by Lima et al. [25], who found that all lipid levels of obese children were borderline, without significant differences between obese subjects and controls. However, Zoair et al. [26] observed a highly significant increase of serum cholesterol, LDL, and triglyceride levels in obese children compared to the control group. Also they observed a significant decrease in HDL-cholesterol in obese children compared to normal children.

The absence of significant differences in lipid profile in our results may be attributed to the high intake of saturated fat by $60 \%$ of all studied children.

In this study, obese children showed significantly increased levels of insulin and HOMA-IR as compared to normal children. In addition, insulin was significantly correlated with BMI. These findings were previously reported in other studies [27, 28]. 
The association of seropositivity of Ad 36 in humans, especially in children and adolescents, is still controversial. In this study we tried to determine the prevalence of Ad 36 antibodies in obese and normal Egyptian children. One hundred and twenty-four serum samples from children and adolescents (76 obese subjects and 48 normal subjects serving as controls) were investigated for Ad 36 lgG.

The results showed that seropositivity was detected in only 2 obese children, which represents 2.6\%. This low percentage of Ad 36 in Egyptian children is in line with a study done on sewage samples that were collected from several wastewater treatment plants in Greater Cairo in the same period as our study. The study included 30 sewage samples; only one sample (3.3\%) was positive for Ad 36 using nested polymerase chain reaction (PCR) [29]. This may confirm the low incidence of Ad 36 in the Egyptian children. Similarly to our results, Valere et al. [30] revealed that Ad 36 seroprevalence was $5.5 \%$ and stated that Ad 36 does not play a role in human obesity. On the other hand, some recent studies on children and adolescents showed a strong association between Ad 36 and obesity [31, 32]. Also, the study of Ponterio et al. [33] indicated that some individuals carry Ad 36 in their visceral adipose tissue.

In conclusion, the results of this study did not confirm an association between obesity and infection with Ad 36 in Egyptian children. This indicated that Ad 36 has a limited effect as a causative agent of obesity in the Egyptian community. Socioeconomic class, unhealthy dietary habits, sedentary life and presence of parental obesity showed a strong association with obesity in this period of life. In addition, the results indicated that obesity in children represents a critical risk factor for the development of insulin resistance status.

It is recommended in future that studies for detection of Ad 36 be done on a wide scale among children and adolescents and in different sociodemographic areas as well as in vitro studies to detect the virus in our environments. Moreover, awareness of prevention programs for overweight or obesity must be increased in children and adolescents through publications and symposia for both children and parents. Schools should inform students about the danger of obesity and its outcome, especially if a child is genetically prone to obesity.

\section{Acknowledgments}

We would like to express our gratitude to the National Research Center for giving us the chance to accomplish this study with the help of its competent technicians and the updated equipment and instrumentation.
Also, the authors thank all the candidates who participated in the study and their parents. This study was part of a project supported financially by the National Research Centre, Egypt.

\section{Conflict of interest}

The authors declare no conflict of interest.

\section{References}

1. Ng M, Fleming NM, Robinson M, et al. Global, region$\mathrm{al}$, and national prevalence of overweight and obesity in children and adults during 1980-2013: a systematic analysis for the global burden of disease study 2013. Lancet 2014; 384: 766-81.

2. WHO: Obesity and overweight. Available online: http:// www.who.int/mediacentre/factsheets/fs311/en/2015.

3. Gabbert C, Donohue M, Arnold J, Schwimmer JB Adenovirus 36 and obesity in children and adolescents. Pediatrics 2010; 126: 721-6.

4. WHO: AnthroPlus for personal computers. Manual Software for assessing growth of the world's children and adolescents. Geneva (2009). (http://www.who.int/ growthref/tools/en/).

5. Badawi NES, Barakat AA, El Sherbini SA, Fawzy HM. Prevalence of overweight and obesity in primary school children in Port Said city. Egypt Pediatr Assoc Gazet 2013; 61: 31-6.

6. Taha AA, Marawan HM. Socio-behavioral determinants of overweight and obesity in Egyptian primary school children. J Child Adolesc Behav 2015; 3: 236.

7. Pasarica M, Dhurandhar NV. Infectobesity: obesity of infectious origin. Adv Food Nutr Res 2007; 52: 61-102.

8. Dhurandhar NV. Is obesity caused by an adenovirus? Expert Rev Antiinfect Ther 2012; 10: 521-4.

9. Almgren M, Atkinso R, He J, et al. Adenovirus-36 is associated with obesity in children and adults in Sweden as determined by rapid ELISA. PLoS One 2012; 7: e41652.

10. Na HN, Kim J, Lee HS, et al. Association of human adenovirus-36 in overweight Korean adults. Int J Obes (Lond) 2012; 36: 281-5.

11. Fossati P, Prencipe L. Serum triglycerides determined colorimetrically with an enzyme that produces hydrogen peroxide. Clin Chem 1982; 28: 2077-83.

12. Burstein M, Scholnick H, Morfin R. Rapid method for the isolation of lipoproteins from human serum by precipitation with polyanions. J Lipid Res 1970; 11: 583-95.

13. Friedewald WT, Levy RI, Fredrickson DS. Estimation of the concentration of low-density lipoprotein cholesterol in plasma, without use of the preparative ultracentrifuge. Clin Chem 1972; 18: 499-502.

14. Barham D, Trinder P. An improved colour reagent for the determination of blood glucose by the oxidase system. Analyst 1972; 97: 142-51.

15. Fossati P, Prencipe L, Berti G. Use of 3,5-dichloro-2-hydroxybenzenesulfonic acid/4-aminophenazone chromogenic system in direct enzymic assay of uric acid in serum and urine. Clin Chem 1980; 31: 227-35.

16. Turkington RW, Estkowski A, Link M. Secretion of insulin or connecting peptide: a predictor of insulin dependence of obese "diabetics". Arch Intern Med 1982; 142: 1102-5.

17. Bonora E, Targher G, Alberiche M, et al. Homeostasis model assessment closely mirrors the glucose clamp technique in the assessment of insulin sensitivity: stud- 

Heba El Malt

ies in subjects with various degrees of glucose tolerance and insulin sensitivity. Diabetes Care 2000; 23: 57-63.

18. Smith EM, Gerba CP. Development of a method for detection of human rotavirus in water and sewage. Appl Environ Microbiol 1982; 43: 1440-50.

19. Rose JB, Singh SN, Gerba CP, Kelley LM. Comparison of microporous filters for concentration of viruses from wastewater. Appl Environ Microbiol 1984; 47: 989-92.

20. Katzenelson E, Fattal B, Hostovesky T. Organic flocculation: an efficient second-step concentration method for the detection of viruses in tap water. Appl Environ Microbiol 1976; 32: 838-9.

21. Egypt Demographic and Health Survey. 2014. Accessed in May 2015.

22. Chakar H, Salameh PR. Adolescent obesity in Lebanese private schools. Eur J Pub Health 2006; 16: 648-51.

23. Khader $\mathrm{Y}$, Irshaidat $\mathrm{O}$, Khasawneh M, Amarin Z, Alomari M, Batieha A. Overweight and obesity among school children in Jordan: prevalence and associated factors. Matern Child Health J 2009; 13: 424-31.

24. Mo-suwan L, Tongkumchum P, Puetpaiboon A. Deterterminants of overweight tracking from childhood to adolescence: a 5 y follow up study of Hat Yai schoolchildren. Int J Obes Relat Metab Disord 2000; 24: 1642-7.

25. Lima S, Arrais R, Almeida M, et al. Plasma lipid profile and lipid peroxidation in overweight or obese children and adolescents. J Pediatr 2004; 80: 23-8.

26. Zoair AM, Muhammad KT, Abu-Ammo DE, Motawea MM. Lipid profile and some cardiac functions in children with obesity. Egypt Paediatr Assoc Gazette 2013. 60: 15-22.

27. Habib SA, Saad EA, Elsharkawy AA, Attia ZR. Pro-inflammatory adipocytokines, oxidative stress, insulin, $\mathrm{Zn}$ and $\mathrm{Cu}$ : interrelations with obesity in Egyptian non-diabetic obese children and adolescents. Adv Med Sci 2015; 60: 179-85.

28. De Filippo G, Rendina D, Moccia F, Rocco V, Campanozzi A. Interleukin-6, soluble interleukin-6 receptor/interleukin-6 complex and insulin resistance in obese children and adolescents. J Endocrinol Investig 2015; 38: 339-43.

29. EL-Senousy WM. Adenovirus 36 in 30 sewage samples. Water pollution department NRC (Unpublished data).

30. Valère J, Steve AG, Gert ED, et al. Lack of evidence for the role of human adenovirus-36 in obesity in a European cohort. Obesity 2011; 19: 220-1.

31. Aldhoon-Hainerova $\mathrm{H}$, Zamrazilova $\mathrm{H}$, Atkinson RL, et al. Clinical and laboratory characteristics of 1179 Czech adolescents evaluated for antibodies to human adenovirus 36. Int J Obes 2014; 38: 285-91.

32. Ponterio E, Gnessi L. Adenovirus 36 and obesity: an overview. Viruses 2015; 7: 3719-40.

33. Ponterio E, Cangemi R, Mariani S, et al. Adenovirus 36 DNA in human adipose tissue. Int J Obes 2015; 39: 1761-4. 